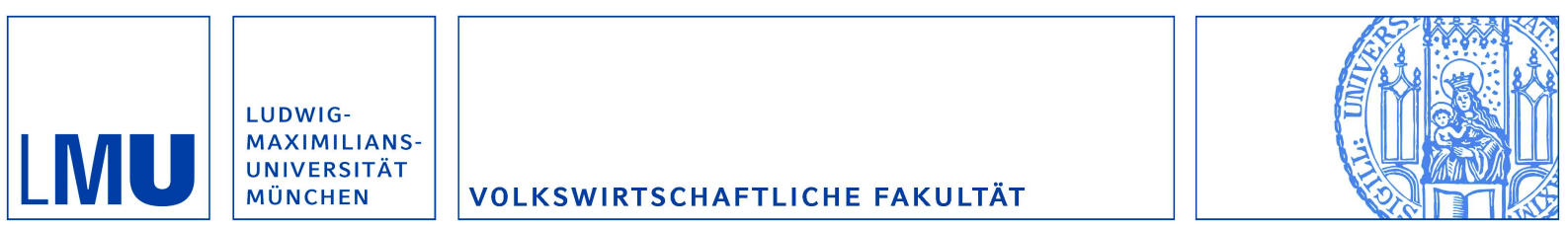

Hendel, Ulrich:

"Look like the innocent flower, but be the serpent under't": Mimicking behaviour of growth-oriented terrorist organizations

Munich Discussion Paper No. 2012-20

Department of Economics

University of Munich

Volkswirtschaftliche Fakultät

Ludwig-Maximilians-Universität München

Online at https://doi.org/10.5282/ubm/epub. 13998 


\title{
"Look like the innocent flower, but be the serpent under't': Mimicking behaviour of growth-oriented terrorist organizations*
}

\author{
Ulrich Hendel ${ }^{\dagger}$
}

\begin{abstract}
This paper examines the interaction between a growth-oriented terrorist organization and an uninformed government based on a two-period signaling game. The terrorists, taking into account the government's counter-terrorism response to first period attacks, gain additional manpower from successful attacks and choose their strategy to maximize the available manpower at the end of period 2. The government tries to infer the terrorist organization's size from the terrorists' attack choice it observes in period 1 and adjusts its second period counter-terrorism spending according to the perceived threat of terrorism. Combining the signaling game and organizational growth approaches of previous contributions, this paper shows that, if a terrorist group follows a growth strategy, it has an incentive to appear weaker than it is by mimicking the behaviour of a smaller organization. Furthermore, depending on its beliefs about the extent of the terrorist threat it can be optimal for a government to spend more on second period counter-terrorism measures if it is not attacked than if it were attacked. The behaviour of contemporary terrorist groups suggests that the assumptions of a growth strategy and mimicking behaviour are justified.
\end{abstract}

JEL Classification: H56, C72, D82

Keywords: terrorism; counter-terrorism; game theory

*I am very grateful to the participants of the Public Economics seminar at the LMU Munich for the productive discussion and to Neil Ferguson, Andreas Haufler, Jana Jarecki, Tim Krieger, Sergey Kuniavsky and Sebastian Stoll for valuable comments. Financial support from the Deutsche Forschungsgemeinschaft through GRK 801 is gratefully acknowledged.

${ }^{\dagger}$ Munich Graduate School of Economics, Ludwig-Maximilians-Universität Munich, Kaulbachstr. 45, D-80539 Munich. Phone: +49 1715328457.

Email: Ulrich.Hendel@lrz.uni-muenchen.de 


\section{Introduction}

Terrorism is one of the big challenges of the $21^{\text {st }}$ century to be overcome by developed Western democracies, emerging nations and developing countries alike. ${ }^{1}$ In 2009, about 11.000 terror attacks took place worldwide, resulting in the death or injury of almost 58.000 people (US Department of State, 2010). In the same year, Europe alone was hit by about 300 terror attacks (Europol, 2010). Apart from very salient attacks in large and developed countries such as $9 / 11$, the bombings in the public transport systems of Madrid and London in 2004 and 2005 and the 2011 attack on the Domodedowo airport in Moscow, most acts of terrorism are perpetrated in developing regions and go largely unreported in Western media. Their direct and indirect effects on the lives and happiness of affected people and on political and economic outcomes are immense, nevertheless. ${ }^{2}$ Terrorism in countries as diverse as Pakistan, Indonesia, Afghanistan and Iraq proves to be a severe danger to the stability of the political system and seriously hampers economic growth. ${ }^{3}$ Terrorism also harms individual firms, distorts trade and forces governments to divert public spending to prevent acts of terror. ${ }^{4}$

Starting with the Al-Qaeda attacks against the USA in 2001, economic research into the economic causes and consequences of terrorism has intensified.

\footnotetext{
${ }^{1}$ As Frey and Luechinger (2003) point out, there is no universally accepted definition of terrorism. In this paper terrorism is thus considered to be any obviously illegal action taken by an organization classified as terrorist such as kidnappings, bank robberies and hijackings.

${ }^{2}$ For an extensive overview over terrorism-related economic research, see Schneider et al. (2010). The impact of terrorism on individual happiness has been the subject of research by Frey et al. (2007). Terrorism-induced fear is the topic of recent work by Becker and Rubinstein (2011), while the socioeconomic determinants of this fear have been examined by Brück and Müller (2009).

Terrorism in Israel has led to a significant shift of parties' political stances towards accommodation of Palestinian interests and "left" policies (Gould and Klor, 2010).

The immediate and short-run impact of terrorism, i.e. the destruction of physical and human capital, may be minor in comparison to long-run effects like additional transactions costs and changes in behaviour and factor prices. See, for instance, Krugman (2004) and cost calculations of the $9 / 11$ aftermath by Penm et al. (2004).

${ }^{3}$ Macroeconomic consequences of terrorism have been examined by, for instance, Abadie and Gardeazabal (2008), Abadie and Gardeazabal (2003), Enders et al. (2006), Blomberg and Mody (2005), Gupta et al. (2004) and Blomberg et al. (2004), with the general result that terrorism hampers growth, deters investment and has the worst effects in developing countries.

${ }^{4}$ In a trade context, terrorism has been modelled as a strategic game played between rational and utility-maximizing governments and terrorist organizations, in which governments decide on border controls and counter-terrorism measures while terror organizations accordingly choose what and how to attack (Mirza and Verdier, 2008).

As measured by market capitalization, Royal Dutch Shell, BP and Coca Cola alone have lost over \$US 20 billion by terror attacks between 1995 and 2002 (Karolyi and Martell, 2006). And between 2001 and 2011, the USA has spent \$US 1.3 trillion on its self-proclaimed "War on Terror" (Belasco, 2009).
} 
It is obvious that in order to develop optimal responses to terrorism, one has to understand the structure of terrorist organization and the nature of the decisions they make. For this purpose game theory is particularly suited. ${ }^{5}$

The aim of this paper is to characterize the interaction between a growthoriented terrorist organization and a government that tries to protect itself from terrorism. To this end the two period signaling game approaches as in Lapan and Sandler (1993), Overgaard (1994) and Arce and Sandler (2007) are combined with an organizational growth framework as in Feinstein and Kaplan (2010). ${ }^{6}$ Terrorists choose their attack strategies according to their initial manpower and expected government counter-terrorism response in order to maximize their manpower at the end of period 2, while governments attempt to infer the size of the terrorist group by its first period actions and adjust their counterterrorism spending accordingly. The governments' counter-terrorism efforts also depend on their ex-ante beliefs about the terrorist group size and the damage governments suffer from attacks.

It turns out that in contrast to the common assumption that (bigger) terrorist attacks increase counter-terrorism efforts, the government response to an attack in the first period is not necessarily higher than if no attack occurs. This is because a government might take a small first period attack as a sign that the resources of the terrorists are not sufficient for a big second period attack. Also, while Lapan and Sandler (1993) and Overgaard (1994) claim that terrorists want to appear as strong as possible, this paper finds that, given that they pursue a growth strategy or derive utility from other sources than government concessions, terrorists may want to appear weaker than they are. This is due to the terrorists' strategic interest to provoke as little counter-terrorism effort as possible so as not to endanger their operations in period 2. This idea is also put forward by Arce and Sandler (2007), but the belief set and response strength of the government are exogenously given. The behaviour of contemporary terrorist groups and counter-terrorism spending trends suggest that the theoretical findings of this paper may be at work in the "real" world. For instance, German right-wing terrorists did not publicly claim responsibility for assassinations of foreign shop owners in the past decade, and there is no obvious connection

\footnotetext{
${ }^{5}$ For instance, Sandler and Arce (2003) present a variety of game theoretic applications to the issue of terrorism, including choice of targets, deterrence vs. pre-emption and others. A different game theoretic approach has been taken by Konrad (2004) to determine the investment decisions of terrorist organizations and subsequent conflict outcomes. For an overview over game theoretic developments in terrorism research, see Sandler and Siqueira (2009).

${ }^{6}$ The signaling games usually contain a third period in which actions are already determined by the two previous periods. I will thus refer to these games as consisting of two periods.
} 
between terror attacks and the budgets of the main German counter-terrorism agencies. Attacks like the Al-Qaeda parcel bombs originating in Yemen in 2010 are exploited particularly for their propaganda value, and it is not clear whether these relatively small attacks should be regarded as a sign of strength and an altered strategy as Al-Qaeda claims, or of a lack of resources and weakness (Die Zeit, 2010, November 2).

As indicated, the contributions by Lapan and Sandler (1993), Overgaard (1994) and Arce and Sandler (2007) which focus on "military" and "political" terrorists (these terms are discussed in section 2) in two period signaling games with asymmetric information are directly related to this paper. Lapan and Sandler (1993) develop a model of military terrorism in which terrorists try to appear as strong as possible to force concessions from a government. Terrorists do this by signaling their strength with an attack in the first period which is used by the government as an indicator whether standing firm and suffering further attacks or giving in and suffering from concessions is the better strategy. Overgaard (1994) models a similar game with political terrorists. Arce and Sandler (2007) present a model in which terrorists differ by type (military or political), and in which the government attempts to distinguish between terrorist types by the size of a first period attack. The authors mention the possibility that military terrorists hold back in period 1 so government retaliation to their second period attack will be lower, but do not endogenously determine the extent of the government response. Furthermore, they assume that the government response will always be stronger if a "spectacular" attack took place in the first period than if only a small attack was perpetrated. In contrast, this paper allows for an endogenous government response that can be less severe even if an attack is observed in the first period. The terrorists' attack decision in the first period is explictly derived as a function of the endogenous government response.

The structure of this paper is as follows: Section 2 discusses the different strategies a terrorist organization may choose and gives examples of particular terrorist groups pursuing these strategies. Sections 3 and 4 develop a model of terrorist-government interaction, while section 5 discusses the results and section 6 concludes. 


\section{Terrorist strategies}

One can distinguish between three different general strategies of terrorist organizations: Influence through violence with violence as an end in itself (military strategy), influence through violence with violence as a mean (political strategy), and growth through violence with violence as a propaganda and advertising tool (growth strategy). ${ }^{7}$

In the case of military terrorists, terrorists act "nihilistic" or vengeful in the sense that attacks are still perpetrated even if there is no chance that the targeted entity will agree to the terrorists' demands. Examples for this strategy are terrorist organizations without affiliated political parties, e.g. the RAF (Rote Armee Fraktion) in Germany. The RAF carried out attacks even though it was clear that the German government would not concede to their demands. ${ }^{8}$ Bernholz (2004) argues that the military type of terrorism is inspired by "supreme values" which are non-negotiable fundamental beliefs. Terrorism is used as a means to violently propagate demands a government would or could never agree to, such as the expulsion of all Jews from the Near East.

In the political case, violence will only be used as long as it has a chance of influencing decisions. If violence has no effect, funds are used for political activities. Terrorists pursuing a political strategy are usually connected with political parties, such as the IRA (Irish Republican Army) with its links to Sinn Fein and the ETA (Euskadi Ta Askatasuna) with its ties to Herri Batasuna. ${ }^{9}$ Organizations engaging in political terrorism usually have limited and negotiable demands such as partial independence or stronger minority rights.

Finally, growth strategies are utilized when a terrorist organization is just starting out, stands in competition with other similar organizations or tries to acquire a certain manpower and fund level to enable a particular operation. Epstein and Gang (2007) argue that terrorist groups benefit from being larger in a rent-seeking contest between terrorist groups where benefits are not related to government concessions. Pursuing a growth strategy which is aimed at becoming the largest terrorist group would also be sensible in this context.

For an exogenous government response, terrorist organizations acting according to a growth strategy have been examined by Feinstein and Kaplan (2010)

\footnotetext{
${ }^{7} \mathrm{~A}$ further differentiation of these strategies and examples can be found in Kydd and Walter (2006).

${ }^{8}$ Amongst these demands were the abolition of capitalism and of the liberal democratic system.

${ }^{9}$ Herri Batasuna was banned by Spain in 2003 due to its terrorist affiliations.
} 
who find that the scale and type of attacks are determined by the initial size of the organization and its "natural growth rate", modeled as a kind of interest on unused manpower. The goal of attacks under this strategy is not primarily to coerce the government into concessions, but to advertise the organization's determination and capabilities to attract recruits and funds by attacks with a high propaganda value. ${ }^{10}$ For instance, Wright (2006) notes that after the 2000 attack on the USS Cole in the port of Aden, "Al-Qaeda camps in Afghanistan filled with new recruits, and contributors from the Gulf States arrived carrying Samsonite suitcases filled with petrodollars." Further examples of terrorist activities which are aimed at increasing the organization's manpower are the Schleyer kidnapping by the RAF and the "Landshut" hijacking by the PFLP (Popular Front for the Liberation of Palestine) in 1977 which were perpetrated to free the first-generation RAF leadership from Stammheim prison.

Amongst the terrorist organizations which found themselves in competition with other groups or had to grow from humble beginnings are the FLN (Front de Libération Nationale) in Algeria, the Tamil Tigers in Sri Lanka and various groups such as Hamas, Fatah, PIJ (Palestinian Islamic Jihad) and PFLP (Popular Front for the Liberation of Palestine) in Palestine. ${ }^{11}$ It can make sense for the terrorist organization to lure governments into a false sense of security to prevent a heavy crackdown in its early stages or to abstain from small attacks with low propaganda value in order not to jeopardize a major attack that is being planned. When observing a terrorist organization pursuing a growth strategy, one would expect an increasing number of attacks with rising intensity over time, as the terrorist group gathers more and more manpower which can in turn be used for further attacks. As shown in Figure 1, this pattern exemplarily becomes visible in the early activities of Hamas, a Palestinian terrorist group, from 1989 until around 1994. For the years following 1994, a change in strategy becomes visible as Hamas focused on fewer but more lethal attacks, which can be seen as a shift towards more expensive, but also more cost-effective large attacks as predicted by Feinstein and Kaplan (2010). ${ }^{12}$

\footnotetext{
${ }^{10}$ For a treatise on the interplay between terrorist attacks, propaganda and the media see Rohner and Frey (2007).

${ }^{11}$ The FLN initially tried to unite the various anti-colonial groups in Algeria and focused on fighting "non-revolutionary" elements in the population, and the Tamil Tigers faced a plethora of similar Tamil groups during the 70's. Ideological and political divisions have led to the creation of several competing Palestinian terrorist groups which vie for public support and influence. See Hoffman and McCormick (2004), Bloom (2004) and Clauset et al. (2010).

${ }^{12}$ The effectiveness of Israeli counter-terrorism measures such as the West Bank barrier during the Second Intifada becomes visible in the drastic reduction of casualties per attack after 2002 .
} 


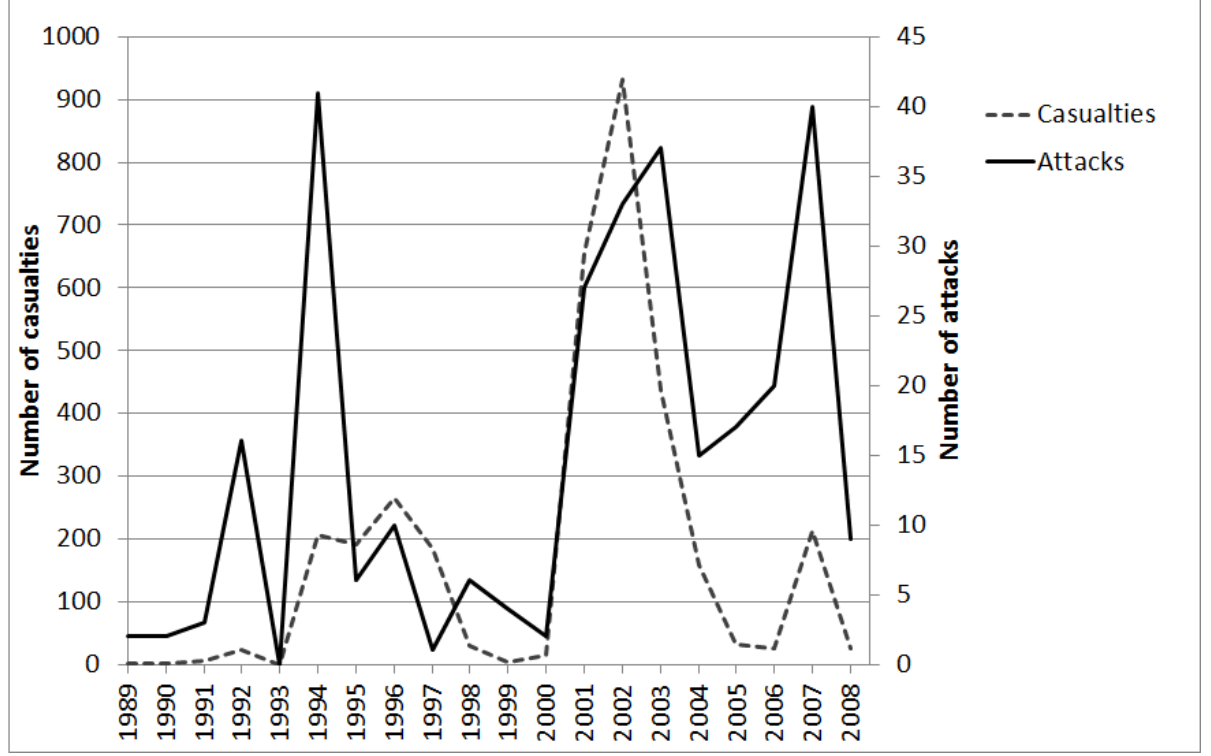

Figure 1: Number and casualties of Hamas attacks between 1989 and 2008. Source: National Consortium for the Study of Terrorism and Responses to Terrorism (2011)

\section{Model}

Assume that the world is populated by two actors, a government and a terrorist organization. These entities are only active in two periods. I first turn to the characterization of the terrorist organization in the absence of an endogenous government response. This basically constitutes a simplified version of the model presented in Feinstein and Kaplan (2010). Feinstein and Kaplan additionally include a choice of scale for terrorist attacks, but this element is not necessary for the analysis of the signaling aspect of the game. ${ }^{13}$

\subsection{Terrorist organization}

The terrorist organization, by attacking the government and benefiting from a positive propaganda effect, maximizes its manpower at the end of the second

\footnotetext{
${ }^{13}$ If terrorists choose both attack type (big/small, see Section 3.1) and scale (continuous function), the government's counter-terrorism response will affect the optimal scale, too. The optimization problem of the terrorists is thus not as straightforward as in the simplified case presented in this paper, but the ordering of attacks with regard to initial manpower would still be the same.
} 
period, given its available manpower $M_{1}$ at the beginning of the first period. ${ }^{14}$ The focus on manpower is justified as it constitutes the main constraint on the extent of terrorist activities (Feinstein and Kaplan, 2010).

Terrorists have two attack options: The first is an attack that requires little planning and manpower effort $C_{s}$ and yields low propaganda benefits $s$. It is carried out at the end of the period in which its planning costs are paid. This kind of attack is called small/type $s$. Given sufficient initial manpower, terrorists are able to perpetrate one small attack in each period. Examples for this kind of terrorist activity are the attacks by the "Juba Sniper" against targets of opportunity (i.e. unaware US soldiers who happened to be at the wrong place at the wrong time) and suicide bombings in public places as in Israel during the Second Intifada. ${ }^{15}$ Hoffman and McCormick (2004) state that only a few days to a few weeks are necessary to recruit, train and deploy a suicide bomber, with very low planning effort and a material cost of around \$US 150 .

The second attack option, called big/type $b$, requires a high manpower and planning effort $C_{b}$ and generates a propaganda benefit of $b$, but also takes two periods to prepare. This means that if the terrorist organization wants to initiate this kind of attack, it can only do so and has to employ the manpower at the beginning of the first period, while the actual attack will not take place until the end of the second period. A prime example of this kind of terrorist attack is $9 / 11$ which took several years to prepare, involved dozens of operatives and required flight lessons for the terrorist pilots. Manpower is completely used up in an attack, e.g. because the involved operatives are killed or the planners and perpetrators of an attack are subsequently discovered by anti-terror agencies.

In the first period, attacks go through unhindered, but in the second period counter-terrorism efforts are in place which reduce the chance of successfully perpetrating attacks. ${ }^{16}$ The success probability of an attack, given by $\theta$, constitutes a negative function of government counter-terrorism spending, but is assumed to be exogenous in this section. $\theta$ will be discussed in detail in Section

\footnotetext{
${ }^{14}$ The increase in manpower after an attack does not have to come from its propaganda value alone. There are numerous instances in which terrorist organizations attempted to free imprisoned fellow terrorists through their attacks which is an even more direct way of raising the available human resources than propaganda.

${ }^{15}$ The "Juba Sniper" was an individual or a group of individuals who ambushed US soldiers in the Iraqi city of Baghdad with a single sniper gunshot, usually inflicting a casualty.

${ }^{16}$ Introducing exogenous counter-terrorism in the first period would just reduce the benefits terrorists can reap in this period. Thus, the $\theta$-parameter for the first period is omitted as it does not add to the dynamics of the model. It is also possible to assume that the attack in period 1 is directed against another country and thus inflicts no damage upon the government, but is observed nevertheless and thus conveys information about the terrorist group size.
} 
3.2 , and at this point it suffices to say that $\theta=1$ means that the government does nothing at all to prevent terror attacks and that the success probability of an attack is therefore 1 . Similarly, $\theta=0$ implies that every attack attempt is doomed to fail, i.e. the success probability is zero. In the case of a foiled attack attempt, the manpower costs of initiating the attack are lost and no propaganda benefit is generated.

Given sufficient manpower, a terrorist organization can plan both types of attacks in the same period, i.e. it is possible to perpetrate a small attack in the first period while also starting preparations for a big attack in period 2. At the same time, terrorists can only plan one attack of each type in each period, so the set of possible strategies is given by $\left\{\right.$ noattacks, $\left.s_{1}, s_{2}, s_{1} s_{2}, b_{2}, s_{1} b_{2}, s_{1} s_{2} b_{2}, s_{2} b_{2}\right\}$, where the subscripts denote the period in which the attack takes place.

The expected value of the terrorists' utility function $U_{T}$ (similar to the expected amount of manpower at the end of period 2) is given by the expected net benefit of attacks. This net benefit is an attack's propaganda value times its success probability minus its manpower costs. At the same time, a terrorist group is constrained by its available manpower in each period. Therefore, the terrorist organization's expected utility function and its budget constraints look as follows:

$$
\begin{gathered}
E\left(U_{T}\right)=\left(s-C_{s}\right)_{\mid s_{1}}+\left(\theta s-C_{s}\right)_{\mid s_{2}}+\left(\theta b-C_{b}\right)_{\mid b_{2}} \\
M_{1} \geq\left(C_{s}\right)_{\mid s_{1}}+\left(C_{b}\right)_{\mid b_{2}} \\
M_{2}=M_{1}+s_{\mid s_{1}}-\left(C_{s}\right)_{\mid s_{1}}-\left(C_{b}\right)_{\mid b_{2}} \geq\left(C_{s}\right)_{\mid s_{2}}
\end{gathered}
$$

The subscripts $\left|s_{1},\right| s_{2}, \mid b_{2}$ indicate that the term only enters the budget constraint and utility function if an attack of type $s, b$ is planned in period 1,2 . In the first period the terrorist organization can only plan attacks if its initial manpower endowment is sufficiently high to afford at least a small attack. In the second period, terrorists reap the manpower benefit $s$ if they perpetrated a small attack in period 1 and can use this manpower and the manpower left over from period 1 to plan another small attack. The initial manpower $M_{1}$ is drawn from a distribution $\mu$ with support $[0, \infty[$ and cumulative distribution function $G$.

To determine a terrorist organization's best course of action it will also be assumed that the manpower gained through the propaganda value of an attack is higher than the manpower cost of this attack. Furthermore, the cost-benefit ratio of a big attack is sufficiently high in relation to that of a small attack so 
that given the choice, terrorists would rather perpetrate one big attack instead of two small ones. This is another way of expressing the higher returns to scale of a big attack which are assumed in Feinstein and Kaplan (2010). E.g., Al-Qaeda's costs of perpetrating the $9 / 11$ attacks are estimated to be between $\$$ US 400,000 and $\$$ US 500,000 (9/11 Commission Report, 2003), while the resulting direct costs in capital and human losses alone supposedly lie between $\$$ US 20 and $\$$ US 60 billion (Schneider et al., 2010). Including further costs which are difficult to measure such as distortions in consumption behaviour, additional unproductive protection spending and expenditures for the War on Terror which, one could argue, served partly as propaganda for terrorists, makes it clear that the $9 / 11$ attacks had an unprecedented net benefit for the terrorists. ${ }^{17}$ The net benefit of small attacks (which are also not infinitely often repeatable) can be assumed to be much lower. Formally, these conditions can be expressed as

$$
s>C_{s}, b>C_{b}, b-C_{b}>2\left(s-C_{s}\right)
$$

Given this setup and an exogenous $\theta>C_{s} / s$ and $M_{1}$, it is possible to determine a terrorist organization's attack strategy. ${ }^{18}$ The strategy yielding the highest benefit, i.e. the highest manpower at the end of period 2, is to plan both small attacks and also the big attack. If resources are not sufficient for this strategy, only planning the big attack is optimal. And if resources at the beginning of period 1 do not allow the planning of a big attack, perpetrating small attacks twice is optimal. Terrorist organizations can thus be classified according to their initial size (see Table 1 in Appendix A): A "large"-type organization can perpetrate all attacks, a "medium"-type one has sufficient manpower for a big attack, a "small"-type organization can only afford to plan small attacks, and "none"-type terrorists do not have the resources for any kind of attack.

\subsection{Government}

I will now characterize the government's utility function and optimization problem. In the world presented in this model the government faces a tradeoff between investing an exogenously given budget $B$ in an anti-terror technology $t$ which lowers the success probability $\theta$ of utility-reducing terrorist attacks and

\footnotetext{
${ }^{17}$ The direct costs of the London tube bombings in 2005, for instance, are assumed to be less than $£ 1$ billion (GLA Economics, 2006).

${ }^{18} \theta>C_{s} / s$ ensures that the expected benefit from a second period attack outweighs its costs.
} 
investing in a consumption technology $\chi$ with input $x$ from which it derives immediate utility. It is not necessary to be more specific about the exact nature of the anti-terror technology. For the purpose of this paper, protecting vulnerable sites works in the same way as infiltrating terrorist networks and uncovering terrorist plots. ${ }^{19}$ The nature of the consumption technology can also be left fairly general. One could think of non-security related government spending or even of security-related pork-barrel spending that does not enhance protection from terrorist attacks. Coats et al. (2006), for instance, find that funds from the 2004 US Homeland Security grant were allocated to states on a vote-per-capita base rather than in proportion to a state's population, leading to an over-protection of small states with a low terrorism risk.

The utility of the government depends only on the second period. It is assumed that in the first period, the government is simply surprised by the emergence of a terrorist organization or has fixed policies in place which cannot be altered before the second period. In the second period, the government bases its spending decisions on full knowledge about all parameters and the distribution of $M_{1}$. I.e., it knows the damage incurred from each attack type and probability of a particular terrorist organization to emerge, but not which type is really active at the beginning of period 2 and which attacks are being planned. It seems reasonable to assume that governments can infer a somewhat precise distribution and potential damage assessment of the current terrorist threat through intelligence gathering activities, informers and other sources. ${ }^{20}$

The government derives utility from consumption and disutility from the damage inflicted by terrorist attacks which is equal to the propaganda benefit for the terrorists. ${ }^{21}$ The expected value of its utility function $U_{G}$ and its budget constraint thus take the form

$$
\begin{gathered}
E\left(U_{G}\right)=\chi(x)-\theta(t) \times\left(\left(\alpha_{\text {small }}+\alpha_{\text {large }}\right) s+\left(\alpha_{\text {medium }}+\alpha_{\text {large }}\right) b+\alpha_{\text {none }}(0)\right) \\
B=x+t
\end{gathered}
$$

$\alpha_{\text {small }}$ gives the probability (derived from the distribution of the initial man-

\footnotetext{
${ }^{19}$ An extensive literature exists on the choice of counter-terrorism strategy and the allocation of security spending. See, for instance, Powell (2007), Golany et al. (2009), Arce and Sandler (2005) and Enders and Sandler (1993).

${ }^{20}$ For instance, two months before the $9 / 11$ attacks the CIA reported strong evidence of an imminent Al-Qaeda attack. The US government chose not to act on this information, however (Washington Post, 2006, October 1).

${ }^{21}$ Making the government's damage and the terrorists' benefit from an attack asymmetric would simply require the introduction of a scaling parameter.
} 
power $\mu$ and the manpower necessary to initiate an attack) that a small terrorist organization is present in the world and will launch a small attack. Similarly, $\alpha_{\text {medium }}, \alpha_{\text {large }}$ and $\alpha_{\text {none }}$ denote the probabilities that a terrorist organization

of this type is present and will strike in period 2 according to its optimal strategy (see Table 1). The alphas have to add up to one. The characteristics of $\chi$ and $\theta$ are as follows:

$$
\begin{gathered}
\chi(0)=0, \chi^{\prime}(0)=\infty, \chi^{\prime}>0, \chi^{\prime \prime}<0 \\
\theta(0)=1, \theta(\infty)>0, \theta^{\prime}(0)=-\infty, \theta^{\prime}<0, \theta^{\prime \prime}>0
\end{gathered}
$$

These conditions ensure that the success probability of an attack is greater than 0 and equal or smaller than 1 and that it is impossible to have full protection against terrorism. Furthermore, the government will always expend its budget on both technologies. The $\alpha$-probabilities are constructed as follows:

$$
\begin{gathered}
\alpha_{\text {none }}=G\left(C_{s}\right), \alpha_{\text {small }}=G\left(C_{b}\right)-G\left(C_{s}\right) \\
\alpha_{\text {medium }}=G\left(C_{b}+C_{s}\right)-G\left(C_{b}\right), \alpha_{\text {large }}=1-G\left(C_{b}+C_{s}\right)
\end{gathered}
$$

See Figure 2 for a graphical representation.

By differentiating (3) with respect to $x$ and $t$, setting these derivatives equal and utilizing the conditions in (4) and (5) the optimal choices of $t$ and $x$ are implicitly given by

$$
\frac{\partial \chi}{\partial x}=-\frac{\partial \theta}{\partial t}\left(\left(\alpha_{\text {small }}+\alpha_{\text {large }}\right) s+\left(\alpha_{\text {medium }}+\alpha_{\text {large }}\right) b+\alpha_{\text {none }}(0)\right)
$$

From (7), it is obvious that an increase in the damage from attacks and a decrease in the probability that a terror organization of type "none" is present will increase the benefit from spending the budget on $t$. The $\alpha$-probabilities are also linked to the costs of terror attacks (see Figure 2). As these costs decrease, the probability of the emergence of a more powerful terror organization rises, and thus a higher $t$-spending becomes optimal.

\section{Terrorist attacks and government responses}

Having described the autonomous decisions of the terrorist organization and the government I will now turn to the interaction between the two actors. Here, as 


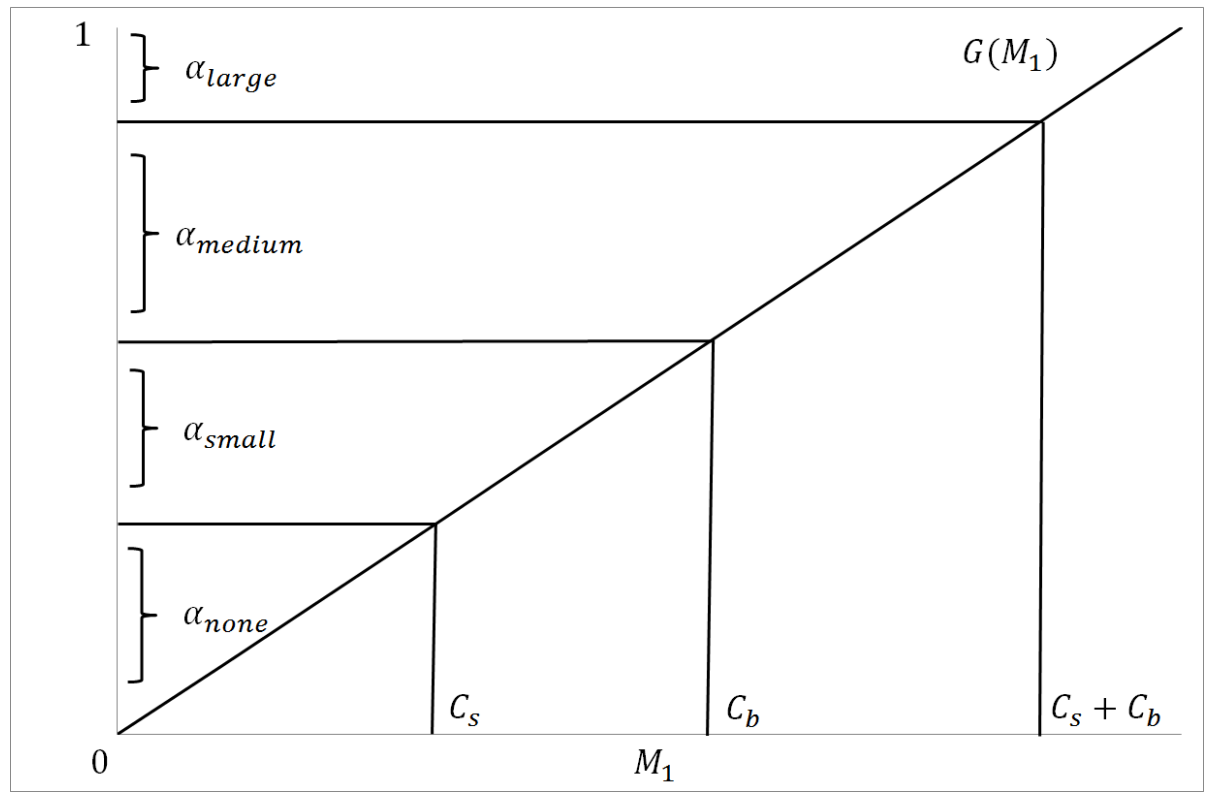

Figure 2: $\alpha$ given $M_{1}$.

commonly assumed in game theoretic models of terrorist-government interactions, terrorists are fully informed about the government's preferences and can thus perfectly anticipate the government's reaction to their actions (c.f. Lapan and Sandler (1993), Overgaard (1994)). The information structure is thus asymmetric, with the government having an informational disadvantage as it does not know which terrorist group size is drawn from the distribution $\mu$.

It will be necessary to determine the government's reaction in two possible cases: First, if a small attack takes place in the first period, and second, if no small attack is launched in the first period. The government will be aware that terrorist organizations might try to hide their true strength and terrorists will no longer take $\theta$ as exogenous. This implies that terrorists in period $1 \mathrm{might}$ want to avoid provoking a severe government response which hampers attacks in period 2 and therefore abstain from attacking in period 1 . I call this pattern of behaviour in which a terror organization wants to appear smaller than it is "mimicking".

To restrict the number of possible scenarios assume that $\theta(B) \times s-C_{s}>0$, so a small attack in period 2 would still be beneficial for the terrorist organization even if the government were to spend its entire budget on counter-terrorism 
measures. ${ }^{22}$ For example, the number of possible targets within a country could be so large that it is not possible to protect all of them sufficiently with a given counter-terrorism budget. This assumption rules out cases in which terrorists abstain from attacking in the second period as the success probability of attacks is too low to justify the planning costs. Under this assumption, the game is solvable by backwards induction. The terrorists' attack decision in the second period which is contingent on the government's counter-terrorism expenditure and the terrorists' first period choice of attacks forms the third stage of the game. The second stage consists of the government's counter-terrorism spending decision which is driven by the terrorist behaviour observed in period 1. Finally, in the first stage it is determined whether the terrorists opt for a small first period and a big second period attack or not. The decision stages and timing of events are given in Figure 3.

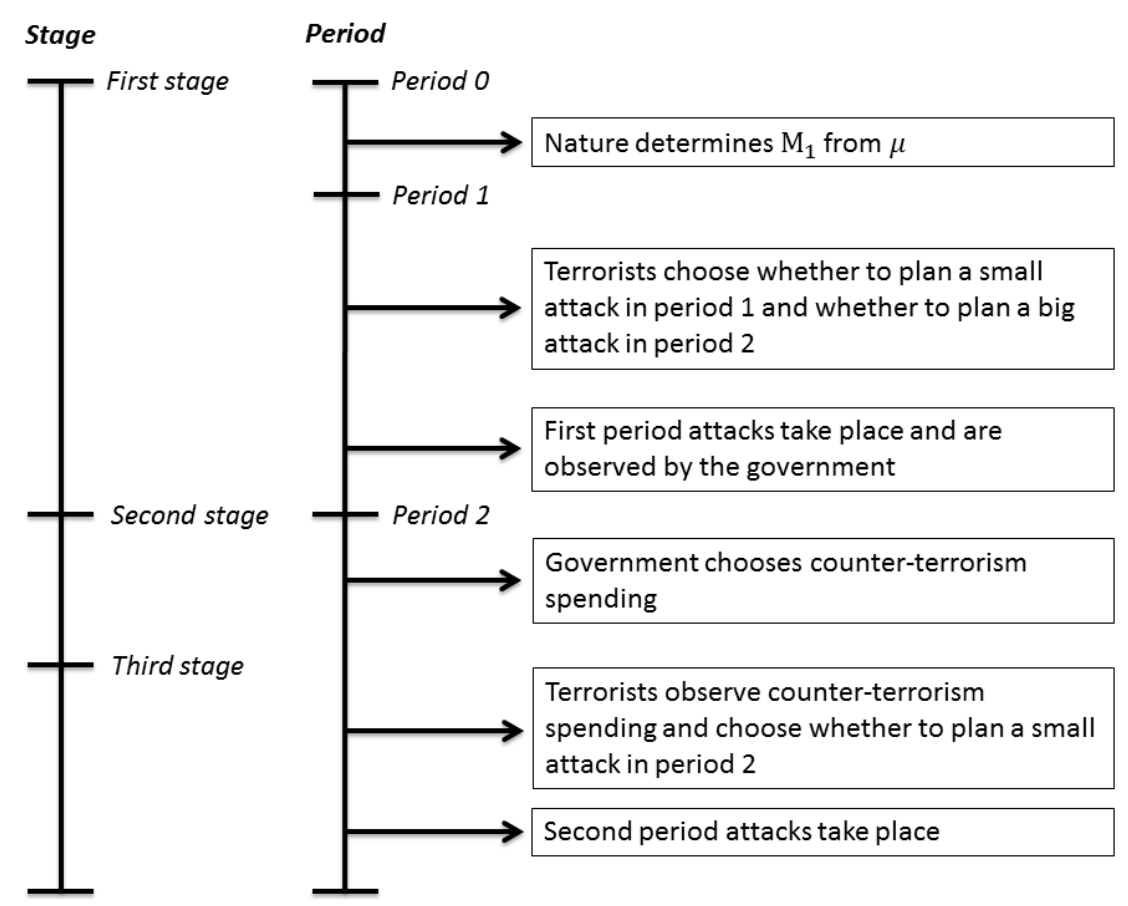

Figure 3: Decision stages and timing of events.

${ }^{22}$ This implies that a large attack is also beneficial as its benefit-cost ratio is higher. 


\subsection{Boundedly rational government}

In this subsection, the government no longer bases its budget allocation decision on $\mu, s$ and $b$ alone, but also on the terrorists' behaviour it observes in period 1. This allows the government to rule out the existence of particular organization types and thus optimize its spending on $t$ by reducing uncertainty. It does not yet, however, take into account the strategic aspect of its decision, i.e. that terrorist behaviour in the first period also depends on the expected counter-terrorism efforts. The model with this kind of bounded rationality is more straightforward and will thus be presented first, but qualitatively the same results are achieved with a fully strategic government as shown in the next subsection.

First, consider the case that the government is hit by a small attack in period 1. The government correctly deduces that neither a terrorist organization of type none nor of type medium can be present as a none type cannot afford to start an attack at all, and a medium type saves its manpower for a big attack in period 2. ${ }^{23}$ The government thus forms posterior beliefs $\beta$ about the odds of facing a small or large terror organization and has an expected utility function of the following form:

$$
E\left(U_{G}\right)=\chi(x)-\theta(t) \times\left(\left(\beta_{\text {small }}+\beta_{\text {large }}\right) s+\beta_{\text {large }} b\right)
$$

The $\beta$-terms are constructed by utilizing Bayes' theorem. In this setup, this amounts to scaling up the prior probability of the emergence of a particular terrorist organization with the remaining probability mass after subtracting the probabilities of terrorist types which cannot be present:

$$
\beta_{\text {large }}=\frac{\alpha_{\text {large }}}{\alpha_{\text {large }}+\alpha_{\text {small }}}
$$

\footnotetext{
${ }^{23}$ The case in which a medium sized group acts like a small sized one will not be considered here. If the counter-terrorism response in period 2 is sufficiently stiff, a medium sized group may find it beneficial to perpetrate two small attacks (one of them unopposed) instead of one big attack. However, this change of strategy cannot be properly described as mimicking because the second period attack can then only be of the small type. The medium terrorist organization not only appears to be a small one in the first period, it also behaves like one in the second period. Also, for a portrayal of the interaction between terrorists and government it is sufficient to show the mimicking behaviour of one type of terrorists and the subsequent government response. To formally rule out the case in which a medium sized group changes its strategy to two small attacks, it would be sufficient to assume that $2\left(s-C_{s}\right)<\theta(B) b-C_{b}$.
} 


$$
\beta_{\text {small }}=\frac{\alpha_{\text {small }}}{\alpha_{\text {large }}+\alpha_{\text {small }}}
$$

After having determined the government's belief if an attack takes place in the first period, assume now the opposite case in which the government is not attacked in period 1 . The government infers that no small terror organization can be active because terrorists of the small type cannot gain anything from abstaining from a first period attack; the benefits from an unopposed small attack in period 1 and a subsequent risky attack in period 2 are always greater than the benefit from initiating just a risky small attack in period 2. Terrorist types none and medium are following their optimal and possible strategies if they do not attack in period 1, but large terror organizations could mimic a medium one to keep the government's response in period 2 at a lower level. The government therefore updates its prior beliefs $\alpha$ to the new probabilities $\gamma$ in the same way as described above and arrives at an expected utility function of the form

$$
E\left(U_{G}\right)=\chi(x)-\theta(t) \times\left(\gamma_{\text {large }} s+\left(\gamma_{\text {large }}+\gamma_{\text {medium }}\right) b+\gamma_{\text {none }}(0)\right)
$$

The $\gamma$-terms are derived in the same way as the $\beta$-terms in (9):

$$
\begin{gathered}
\gamma_{\text {large }}=\frac{\alpha_{\text {large }}}{\alpha_{\text {large }}+\alpha_{\text {medium }}+\alpha_{\text {none }}} \\
\gamma_{\text {medium }}=\frac{\alpha_{\text {medium }}}{\alpha_{\text {large }}+\alpha_{\text {medium }}+\alpha_{\text {none }}} \\
\gamma_{\text {none }}=\frac{\alpha_{\text {none }}}{\alpha_{\text {large }}+\alpha_{\text {medium }}+\alpha_{\text {none }}}
\end{gathered}
$$

It is now possible to predict in which case (small attack/no attack in period 1) the counter-terrorism reaction of the government will be stronger. This is done by calculating the optimal responses for (8) and (10) as in (7) and comparing the terms attached to $\partial \theta / \partial t$. If the expected damage in period 2 , calculated from the updated beliefs about the terrorist group size, is higher if no attack is observed in period 1 than if a small attack takes place, the government will react more strongly in the absence of an attack. Thus, $t$ will be higher when no first period attack takes place if

$$
\gamma_{\text {large }} s+\left(\gamma_{\text {large }}+\gamma_{\text {medium }}\right) b>\left(\beta_{\text {small }}+\beta_{\text {large }}\right) s+\beta_{\text {large }} b
$$




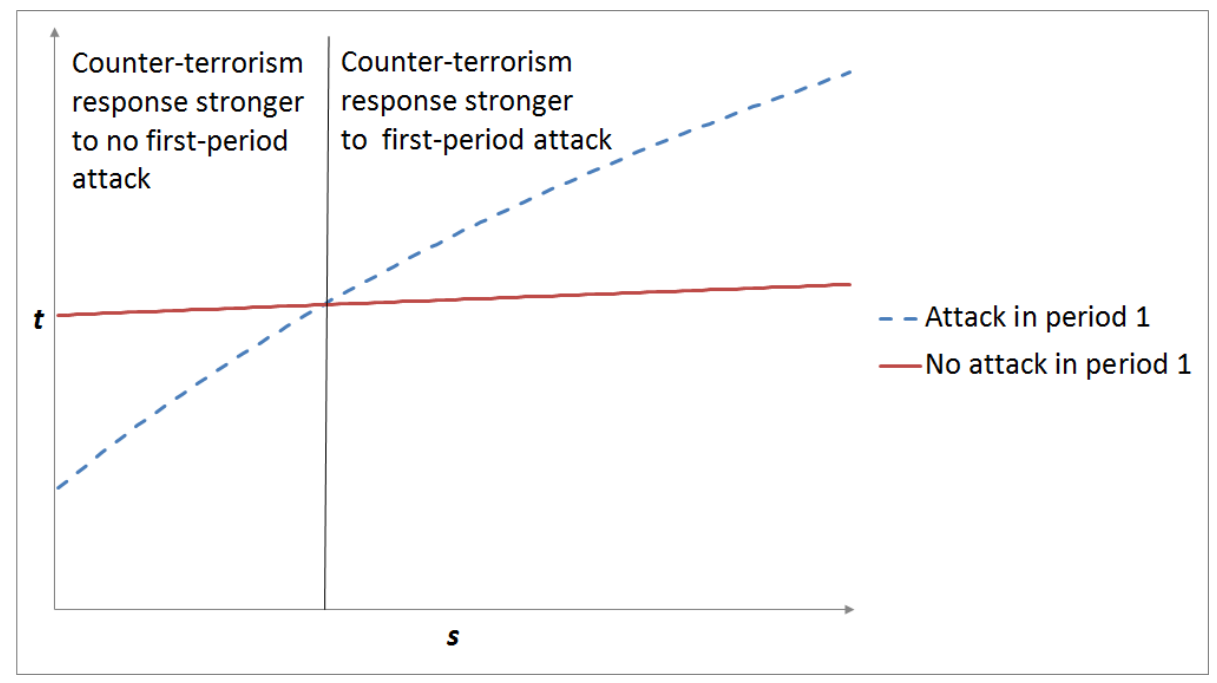

Figure 4: Optimal government response $t$ for varying $s$.

On the left hand side is the damage from a particular attack times the probability of this attack taking place for the no attack case, and on the right hand side the equivalent expression for the attack case. This can be rewritten as

$$
\left(\beta_{\text {small }}+\beta_{\text {large }}-\gamma_{\text {large }}\right) s+\left(\beta_{\text {large }}-\gamma_{\text {large }}-\gamma_{\text {medium }}\right) b<0
$$

For a non-degenerate $\mu$ (that is, a distribution that does not attach probability 1 to a single type), the first term in brackets is always positive. Thus, a necessary but not sufficient condition for (13) to hold is that $\gamma_{\text {large }}+\gamma_{\text {medium }}>\beta_{\text {large }}$, i.e. that the probability of either a large or medium terrorist organization being present in the no attack case has to be higher than the probability of a large terrorist organization being present in the attack case. Furthermore, the damage the government suffers from a big attack has to be large relative to the damage from a small attack for (13) to hold. A higher $s$ will decrease the likelihood that the counter-terrorism reaction in the case of no attack in period 1 is larger. This probability is also decreasing in $\beta_{\text {large }}$ and increasing in $\gamma_{\text {large }}$. This can be summarized in:

Proposition 1: A boundedly rational government will engage in higher counterterrorism spending if no first period attack takes place, if the expected second period damage given the updated government beliefs is higher in the no attack 
case.

Figure 4 gives a graphical example for Proposition 1. Intuitively, the government might reason that the terrorist organization does not have sufficient resources to mount a larger attack in the next period if it observes a small attack in period 1. This is particularly the case when the government draws the conclusion from the assumed distribution of terrorist organization sizes that the existence of a large organization is very unlikely. An observed attack will thus strengthen the belief that a small terrorist organization is active which will only perpetrate a small attack in the next period. Similarly, the absence of an attack may lead the government to believe that a medium terrorist organization or a large terrorist organization mimicking a medium one is plotting against it. It will therefore employ heavier security measures than if an attack in the first period were to take place.

The terrorists will take the aforementioned government decision into account when deciding on their optimal strategy at the onset of period 1 , as it is assumed that they can perfectly anticipate the counter-terrorism response. The mimicking strategy I will focus on here is when a large terrorist organization mimics a medium one by not attacking in period 1 . The case in which a medium terrorist organization acts like a small one will not be considered. A large terrorist organization will find it optimal to abstain from launching a small attack in period 1 if the benefit from a lower counter-terrorism response in period 2 outweighs the loss from foregoing the small attack in period one. Denote by $t_{\mid \gamma}\left(t_{\mid \beta}\right)$ the $t$ resulting from the government's belief set $\gamma(\beta)$. Then, suppressing variables which appear in the same form on both sides, large terrorists will display mimicking behaviour if

$$
\theta\left(t_{\mid \gamma}\right)(b+s) \geq \theta\left(t_{\mid \beta}\right)(b+s)+\left(s-C_{s}\right)
$$

While possibly lowering the government's vigilance in period 2, foregoing a small attack in period 1 means giving up the benefit $\left(s-C_{s}\right)$. From $(13), s$ lowers $\theta\left(t_{\mid \beta}\right)$ relative to $\theta\left(t_{\mid \gamma}\right)$ and thus it is indeterminate whether mimicking behaviour becomes less or more attractive in $s$ as $s$ enters the right-hand side of (14) both positively and negatively. From (14), it is obvious that a large terror organization will never mimic a medium one if (13) holds, that is, if the government's reaction in the absence of an attack is stronger than to an attack. Also, from (13), the more probability the government attaches to $\beta_{\text {large }}$ and the 
less to $\gamma_{\text {large }}$, the higher is the incentive for a large terrorist group to mimic a medium sized one. I.e., the more the government expects a large group to be present in the case of a first period attack and the less in the absence of an attack, the more large groups benefit from hiding their true strength.

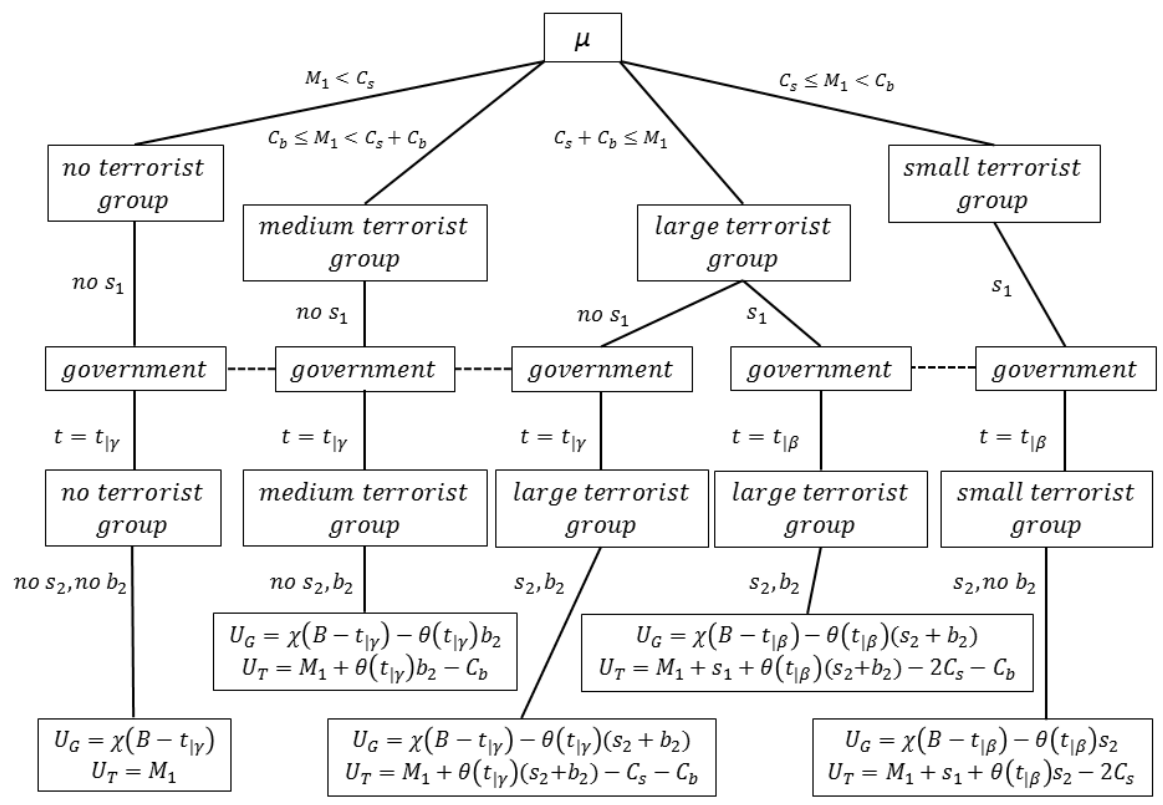

Figure 5: Extensive-form game for a boundedly rational government.

The extensive-form game of the government-terrorist interaction is shown in Figure 5. The mimicking behaviour of large terrorist organizations is summarized in:

Proposition 2: Large terrorist organizations facing a boundedly rational government will mimic medium ones and abstain from launching a small attack in period 1 if the additional expected damage from an increased attack success probability in period 2 is larger than the foregone benefit from a small first period attack.

See Figure 6 for an illustration of Proposition 2. As pointed out in the introduction, terrorists with the goal of exacting concessions from a government, 


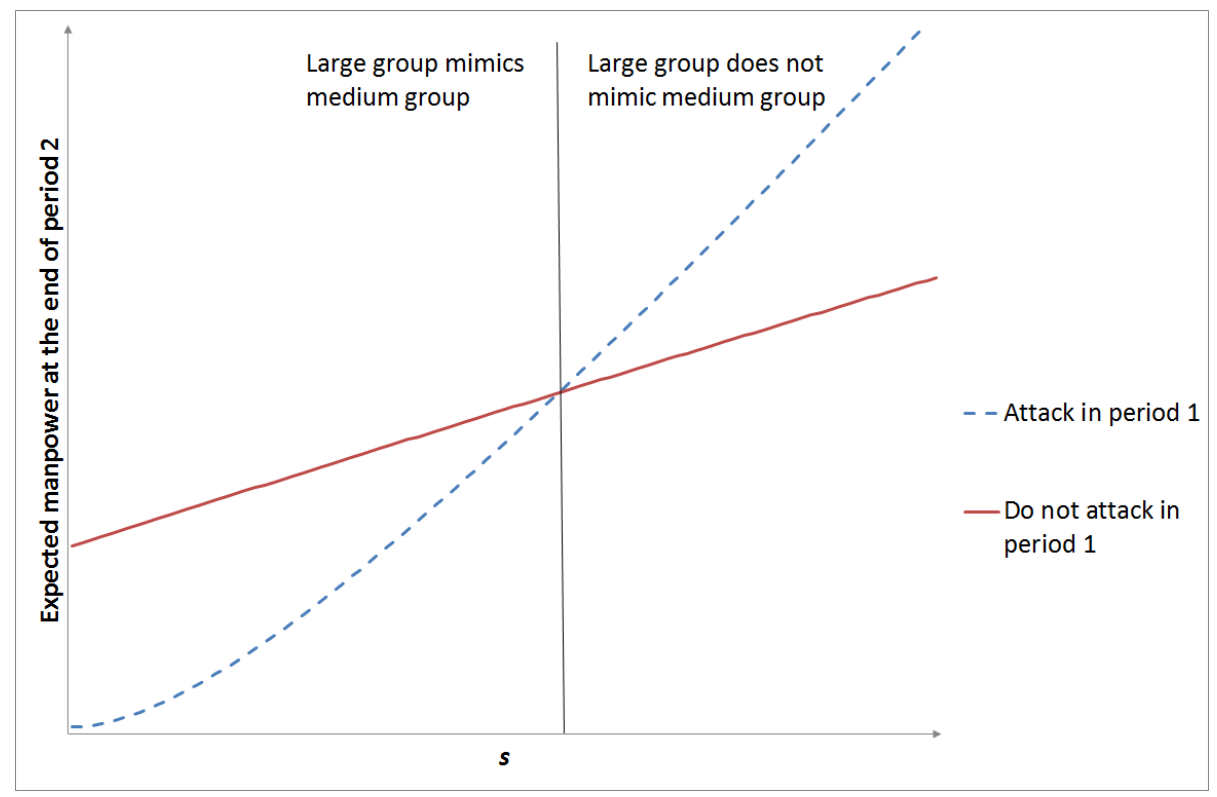

Figure 6: Expected manpower for a large terrorist organization for varying $s$.

such as the ones in the models by Overgaard (1994) and Lapan and Sandler (1993) will want to appear as serious a threat as possible. But this no longer holds if terrorists pursue a growth strategy as in this paper. More generally, if terrorist attacks generate a benefit for the perpetrator apart from the possibility of government concessions, terrorists may want to lure governments into a false sense of security to strike unopposed on a greater scale.

\subsection{Fully rational government}

In the previous section, the government considered that large terrorist groups can mimic medium-sized ones, and can thus be present regardless of whether an attack is observed in the first period or not. However, the government did not take into account that its counter-terrorism spending may not be optimal in the sense that large terrorist groups may have an incentive to always or never mimic, if the government reacts to events in the first period according to the $\beta$ and $\gamma$ probabilities. The updating of the government's beliefs is therefore only boundedly rational in the previous section, as it ignores the strategic implications of the government's actions for the terrorists.

For example, a boundedly rational government does not rule out the possi- 
bility of a large terrorist group being present when it observes no attack in the first period, and chooses $t$ according to the $\gamma$ probabilities. It could now be the case that, given this $t$ which is anticipated by the terrorists, a large terrorist group would have no incentive to mimic as (14) does not hold. The government's counter-terrorism spending level, which is based on updated beliefs erroneously factoring in the possible presence of a large terrorist group, would thus be too high.

This section examines the case in which the government acts fully rational, so it takes into account that the mimicking decision of a large terrorist organization in period 1 depends on the expected reaction of the government in period 2: terrorists anticipate the government's reaction to their first period actions and choose their strategy accordingly. The incidents in the first period are still exogenous for the government as it has no possibility to credibly commit to a counter-terrorism strategy before the terrorists choose their actions. This means that the government's counter-terrorism spending decision does not have to consider the damage that could be averted if the government's strategy encourages large terrorist organizations to abstain from attacking in the first period.

Any strategy a fully rational goverment would choose has to be consistent with its beliefs about the behaviour of the terrorist organizations. Equilibrium strategies of the government and the terrorists therefore have to constitute a perfect Bayesian equilibrium (PBE) in which the terrorists' and government's beliefs about each other's strategy are consistent with their own strategies and vice versa. ${ }^{24}$

A large terrorist organization is indifferent between mimicking and not mimicking a medium-sized one if the gain in expected utility from a lower level of counter-terrorism in the second period is equal to the loss in utility from foregoing a small attack in the first period. This is the case if (14) holds with equality.

Let $t_{A}\left(t_{N A}\right)$ be the counter-terrorism spending level the government chooses if an attack (no attack) takes place in period 1. Furthermore, denote by $t_{\mid \bar{\gamma}}$ the counter-terrorism spending if no first period attack takes place that, given $t_{\mid \beta}$, would make (14) an equality. Similarly, denote by $t_{\mid \bar{\beta}}$ the value of $t_{\mid \beta}$ that, given $t_{\mid \gamma}$, would make (14) an equality if an attack takes place. Thus, by rearranging

\footnotetext{
${ }^{24}$ I also require that beliefs are "structurally consistent" (Mas-Colell et al., 1995, section 9C). I.e., if the government knows that terrorists are indifferent between two options, it cannot possibly assume that one option is chosen with a higher probability than the other.
} 
$(14)$,

$$
\begin{aligned}
& t_{\mid \bar{\gamma}}=\theta^{-1}\left(\theta\left(t_{\mid \beta}\right)+\frac{\left(s-C_{s}\right)}{(b+s)}\right) \\
& t_{\mid \bar{\beta}}=\theta^{-1}\left(\theta\left(t_{\mid \gamma}\right)-\frac{\left(s-C_{s}\right)}{(b+s)}\right)
\end{aligned}
$$

First, I examine the case $t_{\mid \bar{\gamma}}<t_{\mid \gamma}$, so (14) does not hold. If a first period attack takes place, choosing $t_{A}=t_{\mid \beta}$ is optimal for the government as it correctly anticipates the presence of either a small or large terrorist group. But the government knows that if $t_{\mid \bar{\gamma}}<t_{\mid \gamma}$, a large terrorist organization will never mimic a medium one if it sets $t_{N A}=t_{\mid \gamma}$ as by doing so it loses the benefits from the first period attack and is not sufficiently compensated by a reduction in counter-terrorism measures. Thus, $t_{\mid \gamma}$ is an higher-than-optimal level of counterterrorism as it incorrectly assumes the presence of a large terrorist organization and thus too severe a threat.

Ruling out $t_{N A}=t_{\mid \gamma}$ as optimal response leads to two further cases: If the probability of the presence of a medium-sized group is sufficiently high, the government will still engage in higher counter-terrorism spending than $t_{\mid \bar{\gamma}}$ as it faces a high risk of a big attack by a group of type medium. Denote the optimal level of counter-terrorism spending if the government expects a noneor medium-type terrorist organization to be present by $t_{\mid m}$, and assume that $t_{\mid \bar{\gamma}}<t_{\mid m} \cdot{ }^{25}$ The government's strategy $t_{A}=t_{\mid \beta}, t_{N A}=t_{\mid m}$ then constitutes a PBE: If no attack takes place in the first period and the government chooses $t_{N A}=t_{\mid m}$, large terrorist groups will never opt for a mimicking strategy and $t_{N A}=t_{\mid m}$ is optimal for the expected presence of either a terrorist organization of medium or none type. Similarly, if an attack takes place, $t_{A}=t_{\mid \beta}$ is optimal given the possibility that either a small or large group is active, and large groups always perpetrate a small attack in the first period.

In the aforementioned equilibrium, the government chooses a higher level of counter-terrorism spending if it is not attacked in the first period if $t_{\mid \beta}<t_{\mid m}$. From the construction of $t_{\mid \beta}$ and $t_{\mid m}$ this condition is given as

$$
\frac{\alpha_{\text {large }}}{\alpha_{\text {large }}+\alpha_{\text {small }}}+\frac{s}{b}<\frac{\alpha_{\text {medium }}}{\alpha_{\text {medium }}+\alpha_{\text {none }}}
$$

(17) holds if the ratio $\frac{s}{b}$ is small and if the probability of the emergence of a small or medium group is high in comparison to the emergence of a group of type

\footnotetext{
${ }^{25} t_{\mid m}$ is implicitly given by $\frac{\partial \chi}{\partial x}=-\frac{\partial \theta}{\partial t}\left(\left(\frac{\alpha_{\text {medium }}}{\alpha_{\text {medium }}+\alpha_{\text {none }}}\right) b\right)$.
} 
none or large. The behaviour of the government can therefore be summarized in:

Proposition 3: If $t_{\mid \bar{\gamma}}<t_{\mid m}<t_{\mid \gamma}$, a fully rational government will engage in higher counter-terrorism spending if no first period attack takes place

- if the damage from a big attack is large in comparison to the damage from a small attack and

- if the probability of either a small or medium group being active is large in comparison to the probability of the emergence of a group of type none or large.

However, if the probability of the emergence of a medium-sized group is low, $t_{\mid m}<t_{\mid \bar{\gamma}}$ and $t_{\mid m}$ cannot be the optimal level of counter-terrorism spending as at this spending level, mimicking again becomes the strategy of choice for large terrorist organizations. $t_{N A}=t_{\mid m}$ would therefore be lower than optimal as it omits the possible presence of a large terrorist group. It turns out that a pure strategy PBE generally does not exist if $t_{\mid m}<t_{\mid \bar{\gamma}}<t_{\mid \gamma}$. The best the government can do if it does not have a belief-consistent optimal strategy that induces large groups to always or never mimic is to make large groups indifferent. However, a strategy that makes large groups indifferent is belief-consistent only in special cases. The reasoning for these two results is presented in Appendix B.

Now assume that $t_{\mid \bar{\gamma}}>t_{\mid \gamma}$, so (14) holds. If no attack is observed the government sets $t_{N A}=t_{\mid \gamma}$ as it correctly expects the presence of either a none-, medium- or large-type terrorist-organization. But if an attack occurs in the first period, $t_{A}=t_{\mid \beta}$ is no longer optimal as the government knows that at this counter-terrorism spending level large terrorist groups will pursue a mimicking strategy. So only a small terrorist group can be the perpetrator. Denote by $t_{\mid s}$ the optimal counter-terrorism spending if the government expects a small terrorist group to be active. ${ }^{26}$ If $t_{\mid s}>t_{\mid \bar{\beta}}$, the government will set $t_{A}=t_{\mid s}$ as the possible existence of a small terrorist group warrants higher spending than $t_{\mid \bar{\beta}}$. The government's belief that large terrorist organizations will never attack in the first period, in combination with the strategy $t_{A}=t_{\mid s}, t_{N A}=t_{\mid \gamma}$, therefore constitutes a PBE as large terrorist groups will indeed never choose to initiate a first period attack given these $t_{A}$ and $t_{N A}$.

\footnotetext{
${ }^{26} t_{\mid s}$ is implicitly given by $\frac{\partial \chi}{\partial x}=-\frac{\partial \theta}{\partial t}\left(\left(\alpha_{\text {small }}\right) s\right)$.
} 
If $t_{\mid s}<t_{\mid \bar{\beta}}, t_{A}=t_{\mid s}$ cannot be optimal as at this counter-terrorism level large terrorist groups would abandon the mimicking strategy and always attack in the first period. So $t_{A}<t_{\mid \bar{\beta}}$ would be too low, and the government would want to increase its spending. Again, as in the case of $t_{\mid m}<t_{\mid \bar{\gamma}}<t_{\mid \gamma}$, if $t_{\mid \bar{\gamma}}>t_{\mid \gamma}$ and $t_{\mid s}<t_{\mid \bar{\beta}}$ a pure strategy PBE generally will not exist (see Appendix B). The mimicking behaviour of large terrorist organizations if they face a fully rational government is summarized in:

Proposition 4: If $t_{\mid \gamma}<t_{\mid \bar{\gamma}}$ and $t_{\bar{\beta}}<t_{\mid s}$, large terrorist organizations facing a fully rational government will mimic medium ones and abstain from launching a small attack in period 1.

The assumption of a fully rational government thus changes the results of the model in the following ways: There are three mutually exclusive PBE for an appropriate choice of parameter values. In two of these the government will be able to tell which strategy a large terrorist organization will pursue as its choice of counter-terrorism spending uniquely determines the terrorists' optimal strategy. In the third, the government chooses its reaction so as to make large terrorist groups indifferent with regard to attacking or not in the first period. There also exists a range of parameter values for which the model has no pure strategy PBE.

It is still possible that in the absence of an attack counter-terrorism efforts will be higher than if an attack took place. If $t_{\mid \bar{\gamma}}<t_{\mid m}<t_{\mid \gamma}$ and $t_{\mid \beta}<t_{\mid m}$ a fully rational government will react stronger if no first period attack takes place. In contrast, a boundedly rational government as shown in section 4.1 requires that $t_{\mid \beta}<t_{\mid \gamma}$ to have higher counter-terrorism spending in the absence of an attack.

A mimicking strategy is still viable for terrorists given appropriate parameter values, but it occurs under different conditions than in section 4.1 where (14) was required to hold. A large terrorist organization will now pursue a mimicking strategy if $t_{\mid \gamma}<t_{\mid \bar{\gamma}}$ and $t_{\bar{\beta}}<t_{\mid s}$. 


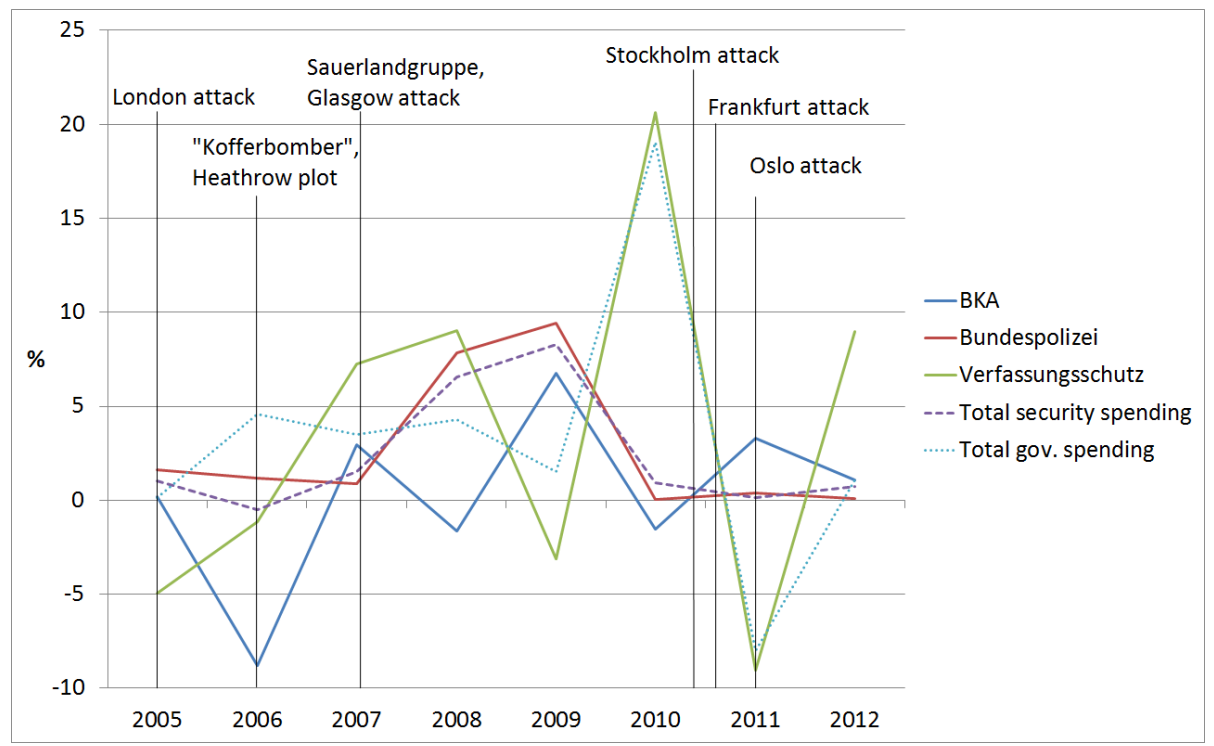

Figure 7: (Attempted) terror attacks in Europe, changes of budgets in \% relative to the previous year for the Federal Criminal Agency (BKA), the German Federal Police (Bundespolizei), the Federal Office for the Protection of the Constitution (Verfassungsschutz) and changes in total spending on these agencies and total government spending without investments and debt service. Source: Bundesministerium der Finanzen (2004-2012)

\section{Discussion}

The previous section has developed a framework to analyze the attack decisions of terrorists and the subsequent counter-terrorism expenditures of governments. This section will discuss the results with attention to real-world observations.

Propositions 1 and 3 state that a terrorist organization's choice to attack does not necessarily evoke a heavier government counter-terrorism response than the choice not to attack. Evidence from Germany shows no clear connection between (attempted) terrorist attacks and expenditures on counter-terrorism measures, i.e. the commonly assumed positive response of counter-terrorism efforts to recent attacks is hard to discern in reality. Figure 7 illustrates that attempted and successful terror attacks (description in Table 2 in Appendix A) in Europe and Germany did not systematically drive up German counter-terrorism spending. Total government expenditures increased faster than security-related spending from 2005 to 2007 regardless of several attacks. In 2008 and 2009, the opposite was the case during a lull of terrorist activity, although one could argue that 
the 2007 attacks triggered the security spending increases. The Verfassungsschutz, however, one of the main German agencies to combat terrorism, slightly reduced its budget in 2009 and increased it again in 2010 by $20 \%$. From 2010 to 2012 , three attacks took place and counter-terrorism spending was fairly stable while total government spending varied wildly due to the financial crisis. ${ }^{27}$ The absence of a discernible positive relationship between terrorist attacks and counter-terrorism budgets is supportive of the notion laid down in Propositions 1 and 3 ; governments may take an attack as an indicator that a terrorist organization has very limited resources or is not of a particularly dangerous size.

Propositions 2 and 4 claim that terrorist organizations may want to appear weaker than they are to avoid a strong government counter-terrorism response which could endanger future operations. While non-growth oriented terrorists are known to threaten attacks if countries do or do not take a particular course of action (e.g., Al-Qaeda threatened to attack Germany if chancellor Merkel were to be reelected in 2009), terrorists with a focus on manpower building should keep quiet so as not to alert the authorities. For instance, the NSU (Nationalsozialistischer Untergrund), a German neo-nazi terror group, did not publicly claim responsibility for its attacks, but circulated propaganda videos of their deeds within the neo-nazi milieu. German authorities did not even attribute most of the attacks to a terrorist organization, but considered them to be part of a turf war between non-native criminals. As current investigations begin to uncover, the three "active" members of the NSU were supported by a considerable network of sympathizers they had built over a decade.

Assessing the real strength of terrorist organizations is a particularly difficult undertaking due to their clandestine nature, loosely affiliated groups and global networks. While terror organizations often boast about their capabilities, communiques in which they claim to be on the wane and weak are rare. But terrorism has been found to follow a cyclical pattern which is indicative of strategic behaviour, i.e. terrorists who engage in inter-temporal substitution to catch governments unprepared (Enders and Sandler, 2002). The intelligence-based updating of beliefs about the magnitude of the terrorist threat in the absence of specific attack announcements shows that some terrorists attempt to appear weak or non-existent prior to attacking. E.g., in late 2010 the German Ministry

\footnotetext{
${ }^{27}$ German counter-terrorism efforts are divided between the BKA, the Bundespolizei and the Verfassungsschutz. Further involved agencies are the federal secret service (Bundesnachrichtendienst) and the military intelligence service (Militärischer Abschirmdienst). It is difficult to determine the funds which are specifically used to combat terrorism within these organizations.
} 
of the Interior announced an increased threat level based on new intelligence and the discovery of several parcel bombs. The terror organizations responsible for this increased threat obviously did not announce their demands or attack plans in advance. Without any attacks taking place, the level of alertness was lowered again in early 2011 (Bundesministerium des Inneren, 2011).

\section{Conclusion}

This paper has integrated the signaling game structure of terrorist attacks as in Lapan and Sandler (1993) into a framework of organizational growth of terrorist groups as in Feinstein and Kaplan (2010). The main findings are that terrorists act rational if they try to hide their true strength and appear weaker than they are, and that governments do not necessarily increase counter-terrorism measures more strongly if they observe a terrorist attack than if no attack takes place. In contrast to the Arce and Sandler (2007) model in which a mechanical government response to a "spectacular" attack can encourage the inter-temporal substitution of attacks by carrying forward resources between periods, this paper shows that first period restraint on part of the terrorists can be aimed at raising the level of uncertainty the government faces.

The driving factor behind these results is that terrorists are interested in organizational growth, not in concessions from the government. Furthermore, their attacks are assumed to have a propaganda value which attracts new recruits. Governments therefore need to be aware that it not only matters whether their terrorist opponents are political or military, but also whether they are currently pursuing a growth strategy. For the prediction and interpretation of terrorist behaviour the differing motivations play an important role, which, as in Arce and Sandler (2007), emphasizes the role of intelligence in the fight against terrorism.

The model could be expanded to include a commitment device such as longterm counter-terrorism investments on the part of the government. This would allow to examine costs and benefits of commitment to a particular counterterrorism strategy, and shed light on the value of real-world policies which create long-term commitments for governments in the struggle against terrorism.

As this paper, in contrast to the discussed literature, argues that terrorists may have an incentive to appear weaker than they are, a further fruitful avenue of research lies in developing a model in which terrorists can signal both weak- 
ness and strength. This would allow to examine the interaction of governments and terrorists if the world is populated by small terrorist groups who may want to appear stronger than they are, and large groups who prefer to appear weak.

\section{References}

9/11 Commission Report (2003), Final Report of the National Commission on Terrorist Attacks upon the United States, New York: W.W. Norton.

Abadie, A. and J. Gardeazabal (2003), The Economic Costs of Conflict: A Case Study of the Basque Country, The American Economic Review, Vol. 93, No. 1, pp. 113-132.

(2008), Terrorism and the world economy, European Economic Review, Vol. 52, No. 1, pp. 1-27.

Arce, D. G. and T. Sandler (2005), Counterterrorism, Journal of Conflict Resolution, Vol. 49, No. 2, pp. 183-200.

(2007), Terrorist Signalling and the Value of Intelligence, British Journal of Political Science, Vol. 37, pp. 573-586.

Becker, G. S. and Y. Rubinstein (2011), Fear and the Response to Terrorism: An Economic Analysis, Mimeo, http://www.econ.brown.edu/fac/yona_rubinstein.

Belasco, A. (2009), The Cost of Iraq, Afghanistan, and Other Global War on Terror Operations Since 9/11, Washington DC: Congressional Research Service.

Bernholz, P. (2004), Supreme values as the basis for terror, European Journal of Political Economy, Vol. 20, No. 2, pp. 317-333.

Blomberg, S. B., G. D. Hess, and A. Orphanides (2004), The macroeconomic consequences of terrorism, Journal of Monetary Economics, Vol. 51, No. 5, pp. 1007-1032.

Blomberg, S. B. and A. Mody (2005), How Severely Does Violence Deter International Investment?, Claremont McKenna College, Working Paper 2005-01. 
Bloom, M. M. (2004), Palestinian Suicide Bombing: Public Support, Market Share, and Outbidding, Political Science Quarterly, Vol. 119, No. 1, pp. 6188.

Brück, T. and C. Müller (2009), Comparing the Determinants of Concern about Terrorism and Crime, DIW Berlin Discussion Paper 904.

Bundesministerium der Finanzen (2004-2012), Bundeshaushalt, http://www.bundesfinanzministerium.de/.

Bundesministerium des Inneren (2011), Statement Bundesinnenminister de Maizière zur Sicherheitslage, 01.02.2011, http://www.bmi.bund.de/SharedDocs/Pressemitteilungen.

Clauset, A., L. Heger, M. Young, and K. S. Gleditsch (2010), The strategic calculus of terrorism: Substitution and competition in the Israel-Palestine conflict, Cooperation and Conflict, Vol. 45, No. 1, pp. 6-33.

Coats, R., G. Karahan, and R. Tollison (2006), Terrorism and pork-barrel spending, Public Choice, Vol. 128, pp. 275-287.

Die Zeit (2010, November 2), Wie al-Qaida sich im Jemen eingerichtet hat, http://www.zeit.de.

Enders, W., A. Sachsida, and T. Sandler (2006), The Impact of Transnational Terrorism on U.S. Foreign Direct Investment, Political Research Quarterly, Vol. 59, No. 4, pp. 517-531.

Enders, W. and T. Sandler (1993), The Effectiveness of Antiterrorism Policies: A Vector-Autoregression-Intervention Analysis, The American Political Science Review, Vol. 87, No. 4, pp. 829-844.

- (2002), Patterns of Transnational Terrorism, 1970-1999: Alternative Time-Series Estimates, International Studies Quarterly, Vol. 46, No. 2, pp. $145-165$.

Epstein, G. S. and I. N. Gang (2007), Who Is the Enemy?, Defense and Peace Economics, Vol. 18, No. 6, pp. 469-484.

Europol (2010), TE-SAT 2010: EU Terrorism Situation and Trend Report, http://www.consilium.europa.eu/uedocs/cmsUpload/TE-SAT\%202010.pdf. 
Feinstein, J. S. and E. H. Kaplan (2010), Analysis of a Strategic Terror Organization, Journal of Conflict Resolution, Vol. 54, No. 2, pp. 281-302.

Frey, B. S. and S. Luechinger (2003), Measuring Terrorism, Institute for Empirical Research in Economics, Working Paper, No. 171.

Frey, B. S., S. Luechinger, and A. Stutzer (2007), Calculating Tragedy: Assessing the Costs of Terrorism, Journal of Economic Surveys, Vol. 21, No. 1, pp. 1-24.

GLA Economics (2006), GLA Economics Annual Report 2006, London: Greater London Authority.

Golany, B., E. H. Kaplan, A. Marmur, and U. G. Rothblum (2009), Nature plays with dice - terrorists do not: Allocating resources to counter strategic versus probabilistic risks, European Journal of Operational Research, Vol. 192, No. 1, pp. 198-208.

Gould, E. D. and E. F. Klor (2010), Does Terrorism Work?, The Quarterly Journal of Economics, Vol. 125, No. 4, pp. 1459-1510.

Gupta, S., B. Clements, R. Bhattacharya, and S. Chakravarti (2004), Fiscal consequences of armed conflict and terrorism in low- and middle-income countries, European Journal of Political Economy, Vol. 20, No. 2, pp. 403-421.

Hoffman, B. and G. H. McCormick (2004), Terrorism, Signaling, and Suicide Attack, Studies in Conflict \& Terrorism, Vol. 27, No. 4, pp. 243-281.

Karolyi, G. A. and R. Martell (2006), Terrorism and the Stock Market, Mimeo, http://papers.ssrn.com/sol3/papers.cfm?abstract_id=823465.

Konrad, K. A. (2004), The Investment Problem in Terrorism, Economica, Vol. 71, No. 283, pp. 449-459.

Krugman, P. (2004), The costs of terrorism: What do we know?, Mimeo, http://www.120.org/publications/9_7Q_wmd_krugman.pdf.

Kydd, A. H. and B. F. Walter (2006), The Strategies of Terrorism, International Security, Vol. 31, No. 1, pp. 49-80.

Lapan, H. E. and T. Sandler (1993), Terrorism and signalling, European Journal of Political Economy, Vol. 9, No. 3, pp. 383-397. 
Mas-Colell, A., M.D. Whinston, and J.R. Green (1995), Microeconomic Theory, New York: Oxford University Press.

Mirza, D. and T. Verdier (2008), International trade, security and transnational terrorism: Theory and a survey of empirics, Journal of Comparative Economics, Vol. 36, No. 2, pp. 179-194.

National Consortium for the Study of Terrorism and Responses to Terrorism (START) (2011), Global Terrorism Database [Data file], http://www.start.umd.edu/gtd.

Overgaard, P. B. (1994), The Scale of Terrorist Attacks as a Signal of Resources, Journal of Conflict Resolution, Vol. 38, No. 3, pp. 452-478.

Penm, J., B. Buetre, and Q. T. Tran (2004), Economic costs of terrorism, abare eReport 04.8., http://143.188.17.20/data/warehouse/pe_abarebrs99001072/PC12719.pdf.

Powell, R. (2007), Defending against Terrorist Attacks with Limited Resources, American Political Science Review, Vol. 101, No. 3, p. 527.

Rohner, D. and B.S. Frey (2007), Blood and ink! The common-interest-game between terrorists and the media, Public Choice, Vol. 133, pp. 129-145.

Sandler, T. and D. G. Arce (2003), Terrorism \&3 Game Theory, Simulation \& Gaming, Vol. 34, No. 3, pp. 319-337.

Sandler, T. and K. Siqueira (2009), Games and Terrorism, Simulation \& Gaming, Vol. 40, No. 2, pp. 164-192.

Schneider, F. G., T. Brück, and D. Meierrieks (2010), The Economics of Terrorism and Counter-Terrorism: A Survey (Part I and II), DIW Berlin Discussion Papers 1049 and 1050.

US Department of State (2010), Country Reports on Terrorism 2009, http://www.state.gov/documents/organization/170479.pdf.

Washington Post (2006, October 1), Two Months before 9/11, an Urgent Warning to Rice, http://www.washingtonpost.com.

Wright, L. (2006), The Looming Tower: Al-Qaeda and the Road to 9/11, New York: Knopf. 


\section{Appendix A: Tables}

\begin{tabular}{|c|c|c|c|}
\hline $\begin{array}{c}\text { Type of } \\
\text { terror orga- } \\
\text { nization }\end{array}$ & Initial size & $\begin{array}{l}\text { Optimal } \\
\text { strategy }\end{array}$ & Example \\
\hline None & $M_{1}<C_{s}$ & No attacks & - \\
\hline Small & $\begin{array}{c}C_{s} \leq M_{1}< \\
C_{b}\end{array}$ & $s_{1}, s_{2}$ & $\begin{array}{c}\text { NSU (Germany), nine } \\
\text { assassinations of foreign } \\
\text { businessmen between } 2000 \text { and } \\
2006 \text { and two bomb attacks }\end{array}$ \\
\hline Medium & $\begin{array}{c}C_{b} \leq M_{1}< \\
C_{s}+C_{b}\end{array}$ & $b_{2}$ & $\begin{array}{l}\text { Al-Qaeda, simultaneous } \\
\text { bombings of the American } \\
\text { embassies in Kenya and } \\
\text { Tanzania in } 1998\end{array}$ \\
\hline Large & $\begin{array}{c}C_{b}+C_{s} \leq \\
M_{1}\end{array}$ & $s_{1}, s_{2}, b_{2}$ & $\begin{array}{c}\text { RAF (Germany), bank } \\
\text { robberies, } \\
\text { assassinations / kidnappings of } \\
\text { prominent Germans, } \\
\text { Stockholm embassy attack in } \\
\text { the ' } 70 \text { s }\end{array}$ \\
\hline
\end{tabular}

Table 1: Optimal terrorist organization strategies based on $M_{1}$ with exogenous government response and corresponding stylized examples. 


\begin{tabular}{|c|c|c|c|c|}
\hline Name & Date & Description & Outcome & Casualties \\
\hline London attack & $\begin{array}{l}\text { July } \\
2005\end{array}$ & $\begin{array}{l}\text { Suicide attacks on } \\
\text { London's public } \\
\text { transport system. }\end{array}$ & $\begin{array}{l}4 \text { suicide terrorists } \\
\text { successfully } \\
\text { detonated their } \\
\text { bombs during the } \\
\text { morning } \\
\text { rush-hour. }\end{array}$ & $\begin{array}{c}52 \text { dead, over } \\
700 \text { injured }\end{array}$ \\
\hline "Kofferbomber" & $\begin{array}{l}\text { July } \\
2006\end{array}$ & $\begin{array}{l}\text { Attempt to blow } \\
\text { up two German } \\
\text { suburban trains. }\end{array}$ & $\begin{array}{l}\text { Bombs did not } \\
\text { explode and were } \\
\text { discovered, } 2 \\
\text { terrorists arrested. }\end{array}$ & - \\
\hline Heathrow plot & $\begin{array}{c}\text { August } \\
2006\end{array}$ & $\begin{array}{c}\text { Attempt to } \\
\text { detonate bombs } \\
\text { on at least } 10 \\
\text { transatlantic } \\
\text { flights. }\end{array}$ & $\begin{array}{c}\text { Plot discovered } \\
\text { before the attack } \\
\text { could be carried } \\
\text { out, several } \\
\text { terrorists arrested. }\end{array}$ & - \\
\hline Sauerlandgruppe & $\begin{array}{c}\text { September } \\
2007\end{array}$ & $\begin{array}{c}\text { Preparations for } \\
\text { assassinations and } \\
\text { bomb attacks. }\end{array}$ & $\begin{array}{c}\text { No attacks } \\
\text { perpetrated, } 4 \\
\text { alleged terrorists } \\
\text { arrested. }\end{array}$ & - \\
\hline Glasgow attack & $\begin{array}{l}\text { June } \\
2007\end{array}$ & $\begin{array}{l}\text { Car loaded with } \\
\text { propane gas } \\
\text { canisters driven } \\
\text { into Glasgow } \\
\text { International } \\
\text { Airport. }\end{array}$ & $\begin{array}{l}\text { No serious fire } \\
\text { ensued, both } \\
\text { terrorists were } \\
\text { apprehended. }\end{array}$ & 5 injured \\
\hline Stockholm attack & $\begin{array}{c}\text { December } \\
2010\end{array}$ & $\begin{array}{l}\text { Car bomb and a } \\
\text { backpack with } \\
\text { pipe bombs } \\
\text { detonated in } \\
\text { Stockholm. }\end{array}$ & $\begin{array}{c}\text { Car bomb went } \\
\text { off, terrorist killed } \\
\text { by his own pipe } \\
\text { bomb. }\end{array}$ & 2 injured \\
\hline Frankfurt attack & $\begin{array}{l}\text { March } \\
2011\end{array}$ & $\begin{array}{c}\text { Islamist gunman } \\
\text { attacking a USAF } \\
\text { bus at Frankfurt } \\
\text { airport. }\end{array}$ & $\begin{array}{l}\text { Gunman shot } \\
\text { several soldiers } \\
\text { and was then } \\
\text { apprehended by } \\
\text { the police. }\end{array}$ & $\begin{array}{c}2 \text { dead, } 2 \\
\text { injured }\end{array}$ \\
\hline Oslo attack & $\begin{array}{l}\text { July } \\
2011\end{array}$ & $\begin{array}{c}\text { Car bomb } \\
\text { detonated in Oslo, } \\
\text { gunman attacks } \\
\text { youth summer } \\
\text { camp. }\end{array}$ & $\begin{array}{l}\text { Car bomb went } \\
\text { off, gunman was } \\
\text { apprehended after } \\
\text { a shooting spree. }\end{array}$ & $\begin{array}{c}77 \text { dead, } 151 \\
\text { injured }\end{array}$ \\
\hline
\end{tabular}

Table 2: Description of terror attacks plotted in Figure 7. 


\section{Appendix B: Absence of PBE if $t_{\mid m}<t_{\mid \bar{\gamma}}<t_{\mid \gamma}$ or $t_{\mid \gamma}<t_{\mid \bar{\gamma}}, t_{\mid s}<t_{\mid \bar{\beta}}$}

\section{With a non-indifferent large terrorist group}

There are two belief-consistent strategies for the government with non-indifferent large terrorist groups: One in which the government chooses its spending so as to make large terrorist groups always attack in the first period, and one in which the counter-terrorist spending makes a large terrorist group always mimic a medium one. However, neither of these strategies is optimal if the chance of the appearance of a medium-sized terrorist group is low $\left(t_{\mid m}<t_{\mid \bar{\gamma}}<t_{\mid \gamma}\right)$ or if it is unlikely that a small group is active $\left(t_{\mid \gamma}<t_{\mid \bar{\gamma}}, t_{\mid s}<t_{\mid \bar{\beta}}\right)$. The government is either over- or underspending and always wants to readjust its counter-terrorism efforts to the point where the strategies are no longer belief-consistent.

Assume first that $t_{\mid m}<t_{\mid \bar{\gamma}}<t_{\mid \gamma}$. If the government sets $t_{\mid m}<t_{\mid \bar{\gamma}}<t_{N A}$, $t_{A}=t_{\mid \beta}$ and expects large groups to always attack, large terrorists groups indeed always attack in the first period, but the government is overspending if no first period attack occurs. It thus wants to reduce $t_{N A}$ to $t_{\mid m}$. But once the spending (if no attack occurs) makes large terrorist groups indifferent with regard to mimicking ( at $t_{N A}=t_{\mid \bar{\gamma}}$ ), the government's belief that large terrorist groups always attack is no longer correct.

Alternatively, the government expects large groups to always mimic and sets

$t_{A}=t_{\mid s}$ and $t_{N A}$ so low that large groups prefer not to attack, the strategy is belief-consistent, but the government is underspending if no first period attack occurs. It therefore wants to increase $t_{N A}$ to $t_{\mid \gamma}$, but once the spending (if no attack occurs) makes large terrorist groups indifferent with regard to mimicking, the government's belief that large terrorist groups never attack is no longer correct.

Now assume that $t_{\mid \gamma}<t_{\mid \bar{\gamma}}, t_{\mid s}<t_{\mid \bar{\beta}}$. If the government sets $t_{N A}=t_{\mid m}$ and $t_{A}$ so low that large groups always want to attack, the government's beliefs are consistent with the terrorist group's behaviour, but it is underspending if a first period attack occurs. Therefore, the government wants to increase $t_{A}$ to $t_{\mid \beta}$, but once the spending if an attack occurs becomes high enough to make large terrorist groups indifferent with regard to mimicking, the government's belief that large terrorist groups always attack is no longer correct.

If the government sets $t_{N A}=t_{\mid \gamma}, t_{\mid s}<t_{\mid \bar{\beta}}<t_{A}$ and expects large groups to mimic medium ones, large terrorist groups indeed never attack in the first 
period, but the government is overspending if a first period attack occurs. It thus wants to reduce $t_{A}$ to $t_{\mid s}$, but once the spending if no attack occurs makes large terrorist groups indifferent with regard to mimicking $\left(\right.$ at $\left.t_{A}=t_{\mid \bar{\beta}}\right)$, the government's belief that large terrorist groups never attack is no longer correct.

It follows from this discussion that the only belief-consistent and optimal strategy the government can pick in all cases is to choose $t_{A}$ and $t_{N A}$ so as to make large groups indifferent with regard to mimicking, while taking into account that $t_{A}$ and $t_{N A}$ have to maximize its utility under the belief that large groups choose to attack half of the time. But, as shown below, such a combination of $t_{A}$ and $t_{N A}$ does generally not exist.

\section{With an indifferent large terrorist group}

Assume that $t_{\mid m}<t_{\mid \bar{\gamma}}$ and $t_{\mid s}<t_{\mid \bar{\beta}}$. The government wants to optimize its counter-terrorism spending when large terrorist groups are indifferent between attacking and not attacking in the first period, and thus choose each strategy with the same probability.

The government knows that the chance of a large group being active in both the attack and no attack case is half the conditional probability of a large group being active. If it is attacked in the first period the government hence forms the following belief set, denoted by $\delta$ :

$$
\begin{aligned}
\delta_{\text {large }} & =\frac{0.5 \times \alpha_{\text {large }}}{0.5 \times \alpha_{\text {large }}+\alpha_{\text {small }}} \\
\delta_{\text {small }} & =\frac{\alpha_{\text {small }}}{0.5 \times \alpha_{\text {large }}+\alpha_{\text {small }}}
\end{aligned}
$$

If the government is not attacked it forms the belief set $\varphi$ :

$$
\begin{aligned}
\varphi_{\text {large }} & =\frac{0.5 \times \alpha_{\text {large }}}{0.5 \times \alpha_{\text {large }}+\alpha_{\text {medium }}+\alpha_{\text {none }}} \\
\varphi_{\text {medium }} & =\frac{\alpha_{\text {medium }}}{0.5 \times \alpha_{\text {large }}+\alpha_{\text {medium }}+\alpha_{\text {none }}} \\
\varphi_{\text {none }} & =\frac{\alpha_{\text {none }}}{0.5 \times \alpha_{\text {large }}+\alpha_{\text {medium }}+\alpha_{\text {none }}}
\end{aligned}
$$

From these probabilities, the counter-terrorism levels $t_{A}=t_{\mid \delta}$ and $t_{N A}=t_{\mid \varphi}$ are constructed according to (7). These spending levels are only optimal and consistent with the government's belief that large terrorist groups are indifferent 
if large groups obtain the same utility regardless of whether they attack or not. This, from (14), is the case if

$$
\theta\left(t_{\mid \varphi}\right)(b+s)=\theta\left(t_{\mid \delta}\right)(b+s)+\left(s-C_{s}\right)
$$

or, equivalently,

$$
\theta\left(t_{\mid \varphi}\right)=\theta\left(t_{\mid \delta}\right)+\frac{s-C_{s}}{b+s}
$$

Here, it becomes visible that (21) only holds for particular value combinations of $\alpha, s, b$ and $C_{s}$. It is therefore only in special cases that the government's strategy to set $t_{A}=t_{\mid \delta}, t_{N A}=t_{\mid \varphi}$ under the belief that large terrorist groups are indifferent constitutes a PBE. 